American Journal of Applied Sciences 8 (6): 628-634, 2011

ISSN 1546-9239

(C) 2011 Science Publications

\title{
Variable Viscosity, Chemical Reaction and Thermal Stratification Effects on Mixed Convection Heat and Mass Transfer along a Semi-Infinite Vertical Plate
}

\author{
${ }^{1}$ P. Geetha and ${ }^{2}$ M.B.K. Moorthy \\ ${ }^{1}$ Department of Mathematics, Bannari Amman Institute of Technology, \\ 638 401, Sathyamangalam, \\ ${ }^{2}$ Department of Mathematics, Institute of Road and Transport, 638 316, Erode
}

\begin{abstract}
Problem statement: In this research the researchers studied and made an analysis to the heat and mass transfer characteristics in a viscous fluid over a semi-infinite vertical porous plate by taking into account the variable viscosity, chemical reaction and thermal stratification effects. Approach: The governing partial differential equations were transformed into a set of coupled non-linear ordinary differential equations, which were solved numerically using the R.K. Gill method along with the shooting technique. Results: Numerical results were presented for the distribution of velocity, temperature and concentration profiles within the boundary layer. Conclusion: The effects of different thermo physical parameters like variation in viscosity due to temperature, chemical reaction parameter on the dimensionless velocity, temperature and concentration profiles were examined.
\end{abstract}

Key words: Mixed convection, local similarity, variable viscosity, chemical reaction, thermal stratification, suction parameter, boundary layer, foreign mass, vertical plate, temperaturedependent viscosity

\section{INTRODUCTION}

In many transport processes existing in nature and in industrial applications, heat and mass transfer is a consequence of buoyancy effects caused by diffusion of heat and chemical species. The study of such processes is useful for improving a number of chemical technologies, such as polymer production and food processing. In nature, the presence of pure air or water is impossible. Some foreign mass may be present either naturally or mixed with the air or water. The effect of the presence of foreign mass on the free convection flow past a semi-infinite vertical plate was studied by Gebhart and Pera (1971). The presence of a foreign mass in air or water causes some kind of chemical reaction. During a chemical reaction between two species, heat is also generated (Bird et al., 1992). In most cases of chemical reaction, the reaction rate depends on the concentration of the species itself. A reaction is said to be first order if the rate of reaction is directly proportional to concentration itself (Cussler, 1988). Chemical reaction effects on heat and mass transfer laminar boundary layer flow have been studied by many authors (Apelblat, 1982; Das et al., 1994; Andersson et al., 1994; Fan et al., 1997; Takha et al., 2000; .Muthucumaraswamy and P.Ganesan,
2001; Chamkha, 2003; Kandasamy et al., 2005) in different situations.

The previous studies are based on the constant physical properties of the fluid. For most realistic fluids, the viscosity shows a rather pronounced variation with temperature. It is known that the fluid viscosity changes with temperature (Herwing and Wickern, 1986). So it is necessary to take into account the variation of viscosity with temperature in order to accurately predict the heat transfer rates. The effect of temperature-dependent viscosity on the mixed convection flow from vertical plate has been investigated by several authors (Lai and F.A.Kulachi, 1990; Kafoussius and Williams, 1995; Hady et al., 1996 Kafoussias et al., 1998 Hossain and Munir, 2000). The effects of variable viscosity and chemical reaction on mixed convection heat and mass transfer along a semi- infinite vertical plate have also been studied (Mahmoud, 2007).

The aim of this present work is to study the effects of thermal stratification, variable viscosity and chemical reaction on heat and mass transfer along a semi-infinite vertical plate with suction. The order of chemical reaction in this study is taken as first order reaction.

Corresponding Author: P. Geetha, Department of Mathematics, Bannari Amman, Institute of Technology, 638 401, Sathyamangalam 
Mathematical analysis: Consider a steady, viscous incompressible Newtonian fluid past a semi-infinite vertical porous plate which is aligned parallel to a uniform free stream with velocity $u_{\propto}$. The fluid properties are assumed to be isotropic and constant, except for the chemical reactions and the fluid viscosity which are assumed to be inverse linear functions of temperature (Lai and Kulachi, 1990). It is assumed that the viscous dissipation and the heat generated during chemical reaction are neglected.

The $\mathrm{x}$ - axis is assumed to be taken along the plate and the $y$-axis normal to the plate. The concentration at the plate surface would be $C_{w}$ and the solubility of $A$ in $\mathrm{B}$ and the concentration of $\mathrm{A}$ far away from the plate would be $\mathrm{C}_{\propto}$. Let the reaction of a species $\mathrm{A}$ with $\mathrm{B}$ be first order homogeneous chemical reaction with rate constant $\mathrm{k}_{1}$. It is desired to analyze the system by a boundary layer method. It is assumed that the concentration of dissolved A is small enough and the physical properties $\rho$ and $D$ are virtually constant throughout the fluid. Under the above assumption, the boundary layer equations governing the flow and concentration fields is expressed by I.pop and D.B. Ingham (Pop and Ingham, 2001) as:

$\frac{\partial \mathrm{u}}{\partial \mathrm{x}}+\frac{\partial \mathrm{v}}{\partial \mathrm{y}}=0$

$\mathrm{u} \frac{\partial \mathrm{u}}{\partial \mathrm{x}}+\mathrm{v} \frac{\partial \mathrm{u}}{\partial \mathrm{y}}=\frac{1}{\rho_{\infty}} \frac{\partial}{\partial \mathrm{y}}\left(\mu \frac{\partial \mathrm{u}}{\partial \mathrm{y}}\right)$

$+\mathrm{g} \beta\left(\mathrm{T}-\mathrm{T}_{\infty}\right)+\mathrm{g} \beta^{*}\left(\mathrm{C}-\mathrm{C}_{\infty}\right)$

$\mathrm{u} \frac{\partial \mathrm{T}}{\partial \mathrm{x}}+\mathrm{v} \frac{\partial \mathrm{T}}{\partial \mathrm{y}}=\mathrm{k} \frac{\partial^{2} \mathrm{~T}}{\partial \mathrm{y}^{2}}$

$u \frac{\partial C}{\partial x}+v \frac{\partial C}{\partial y}=D \frac{\partial^{2} C}{\partial y^{2}}-K_{1}\left(C-C_{\infty}\right)$

$\mathrm{T}=\mathrm{T}_{\infty}=(1-\mathrm{M}) \mathrm{T}_{0}+\mathrm{MT}_{\mathrm{w}}(\mathrm{x})$

With the boundary conditions:

$\mathrm{u}=0 ; \mathrm{v}=-\mathrm{v}_{\mathrm{w}} ; \mathrm{C}=\mathrm{C}_{\mathrm{w}} ; \mathrm{T}=\mathrm{T}_{\mathrm{w}} ;$ at $\mathrm{y}=0$

$\mathrm{u} \rightarrow \mathrm{u}_{\infty} ; \mathrm{C} \rightarrow \mathrm{C}_{\infty} ; \mathrm{T} \rightarrow \mathrm{T}_{\infty}$ as $\mathrm{y} \rightarrow \infty$

Introducing the similarity variables:

$\eta=\sqrt{\frac{u_{\infty}}{v_{\infty} x}} y, \psi(x, y)=\sqrt{v_{\infty} u_{\infty} x} f(\eta)$
The velocity components are given by:

$u=\frac{\partial \psi}{\partial y}, v=-\frac{\partial \psi}{\partial x}$

It can be easily verified that the continuity Eq. 1 is identically satisfied. Equations 2-4 reduce to:

$$
\begin{aligned}
& \mathrm{f}^{\prime \prime \prime}+\frac{1}{2}\left(\frac{\theta_{\mathrm{r}}-\theta}{\theta_{\mathrm{r}}}\right) \mathrm{ff}^{\prime \prime}+\frac{\theta^{\prime}}{\left(\theta_{\mathrm{r}}-\theta\right)} \mathrm{f}^{\prime \prime}+ \\
& \frac{\mathrm{Gr}}{\operatorname{Re}^{2}}\left(\frac{\theta_{\mathrm{r}}-\theta}{\theta_{\mathrm{r}}}\right) \theta+\frac{\mathrm{Gc}}{\operatorname{Re}^{2}}\left(\frac{\theta_{\mathrm{r}}-\theta}{\theta_{\mathrm{r}}}\right) \varphi=0 \\
& \theta^{\prime \prime}-\operatorname{Pr}\left(\lambda \mathrm{f}^{\prime} \theta+\frac{\mathrm{M}}{1-\mathrm{M}} \mathrm{f}^{\prime} \lambda-\frac{1}{2} \mathrm{f} \theta^{\prime}\right)=0 \\
& \varphi^{\prime \prime}+\frac{1}{2} \operatorname{Scf} \varphi^{\prime}-\gamma \operatorname{Sc} \operatorname{Re} \varphi=0
\end{aligned}
$$

Where:

$$
\begin{aligned}
& \theta=\frac{T-T \infty}{T_{w}-T_{\infty}} ; \varphi=\frac{C-C_{\infty}}{C_{w}-C_{\infty}} ; \theta_{r}=\frac{-1}{\alpha\left(T_{w}-T_{\infty}\right)} \\
& \operatorname{Re}=\frac{u_{\infty} x}{v_{\infty}} ; G r=\frac{g \beta\left(T_{w}-T_{\infty}\right)}{v_{\infty}^{2}} x^{3} ; G c=\frac{g \beta^{*}\left(C_{w}-C_{\infty}\right)}{v_{\infty}^{2}} x^{3} \\
& \gamma=\frac{k_{1} v_{\infty}}{u_{\infty}^{2}} ; \operatorname{Pr}=\frac{\mu_{\infty} c_{p}}{k} S c \frac{v_{\infty}}{D}
\end{aligned}
$$

$\alpha$ is a constant ( $>0$ for liquids) and ( $<0$ for gases), $v_{\infty}=\frac{\mu_{\infty}}{\rho_{\infty}}$ and the primes denote differentiation with respect to $\eta$.

The transformed boundary conditions are given by:

$\eta=0 ; f=f_{w} ; f^{\prime}=0 ; \theta=1 ; \varphi=1$

$\eta \rightarrow \infty ; f^{\prime} \rightarrow 1 ; \theta \rightarrow 0 ; \varphi \rightarrow 0$

Where:

$\mathrm{f}_{\mathrm{w}}=\sqrt{\frac{\mathrm{x}}{\mathrm{v}_{\infty} \mathrm{u}_{\infty}}} \mathrm{v}_{\mathrm{w}} \quad$ (suction parameter $\left.>0\right)$

The physical quantities of interest in this problem are the local skin-friction coefficient $\mathrm{C}_{\mathrm{fx}}$, the local Nusselt number $\mathrm{N}_{\mathrm{ux}}$ and the local Sherwood number $\mathrm{S}_{\mathrm{hx}}$ which are defined by: 
Am. J. Applied Sci., 8 (6): 628-634, 2011

$$
\begin{aligned}
& \mathrm{C}_{\mathrm{fx}}=\frac{2 \theta_{\mathrm{r}}}{\left(\theta_{\mathrm{r}}-1\right)} \operatorname{Re}^{-\frac{1}{2}} \mathrm{f}^{\prime \prime}\left(0, \theta_{\mathrm{r}}\right), \mathrm{N}_{\mathrm{ux}} \\
& =-\operatorname{Re}^{\frac{1}{2}} \theta^{\prime}\left(0, \theta_{\mathrm{r}}\right), \mathrm{S}_{\mathrm{hx}}=-\operatorname{Re}^{\frac{1}{2}} \varphi^{\prime}\left(0, \theta_{\mathrm{r}}\right)
\end{aligned}
$$

\section{MATERIALS AND METHODS}

Numerical solution: The set of nonlinear ordinary differential Eqs. (9-11) with boundary conditions (12) have been solved by using R K Gill method along with shooting technique. The parameters involved in the present problem are $\theta_{\mathrm{r}}, \mathrm{Gr}, \mathrm{Gc}, \operatorname{Re}, \lambda, \operatorname{Pr}, \mathrm{M}, \mathrm{Sc}$ and $\gamma$. The computation were done by a program which uses a symbolic and computational computer language (Fortran 7.7) on a Pentium 4 PC machine. A step size of $\Delta \eta=0.005$ was selected to be satisfying for a convergence criterion of $10^{-7}$ approximately in all cases.. The value of $\eta_{\infty}$ was found to each iteration loop by the assignment statement $\eta_{\infty}=\eta_{\infty}+\Delta \eta$. The maximum value of $\eta_{\infty}$ to each group of parameters $\theta_{\mathrm{r}}$, Gr, Gc, Re, $\lambda, \operatorname{Pr}, \mathrm{M}, \mathrm{Sc}$ and $\gamma$ determined when the values of unknown boundary conditions at $\eta=0$ not change to successful loop with error less than $10^{-7}$.

\section{RESULT}

Table 1 shows numerical values of effects of various parameters as $f^{\prime \prime}(0),-\theta^{\prime}(0)$ and $-\phi^{\prime}(0)$. The profiles for velocity, temperature and concentration are shown in Fig. 1-12. respectively with various values of the parameters.

\section{DISCUSSION}

It is seen from Fig. 1 that the velocity decreases as $\lambda$ (the power law index) increases for $\mathrm{M}=0$, in the absence of the thermal stratification effect and for $\theta_{\mathrm{r}}=2$, the variable viscosity parameter. It is obvious that near to the plate, the velocity profiles are asymptotic far away from the plate, irrespective of any value for $\lambda$. It is observed from Fig. 2 that the velocity decreases as $\lambda$ increases for $M=0$ and $\theta_{\mathrm{r}}=-5$. From Fig. 1-2 it is clearly understood that these parameters have less influence on the velocity profile.

From Fig. 3, it is visible that the velocity increases with increase of the viscosity parameter. This is true for negative values of $\theta_{\mathrm{r}}$. It is realized that the thermal boundary layer thickness decreases as the viscosity parameter $\theta_{\mathrm{r}}$ increases, irrespective of the thermal stratification parameter $\mathrm{M}$ and power law index $\lambda$. It is understood from Fig. 4 that the velocity profiles are identical irrespective of $\mathrm{M}$. It shows that the thermal stratification parameter $M$ has less influence on velocity distribution.

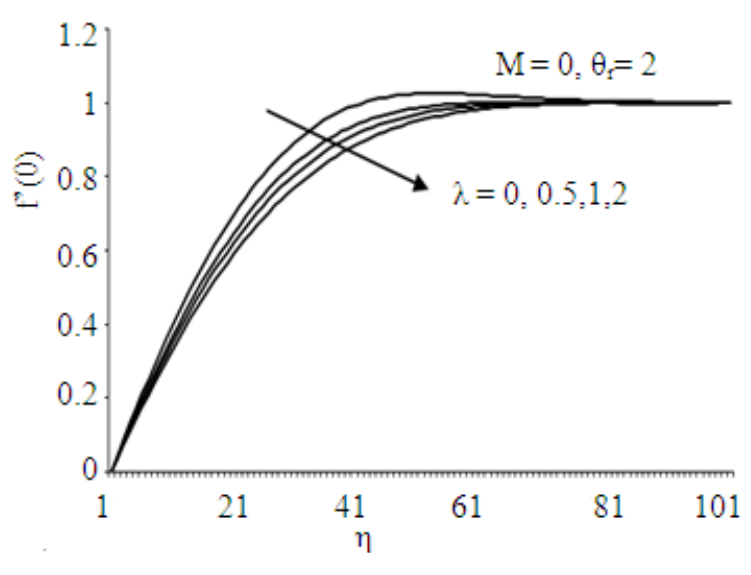

Fig. 1: Velocity profile

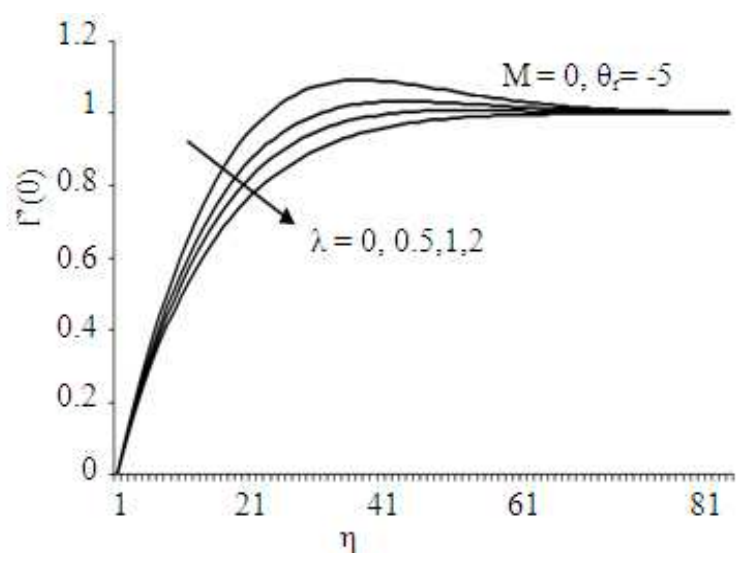

Fig. 2: Velocity profile

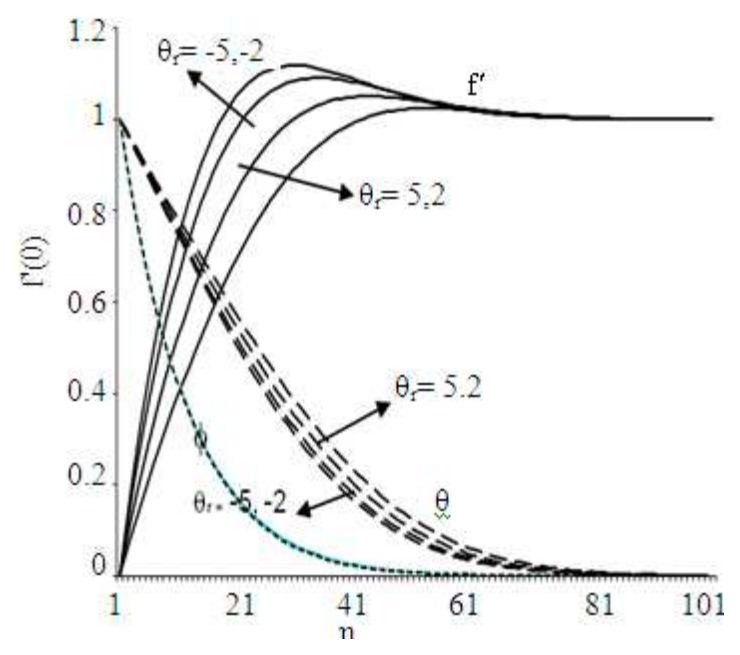

Fig. 3: Velocity, temperature and concentration profiles 


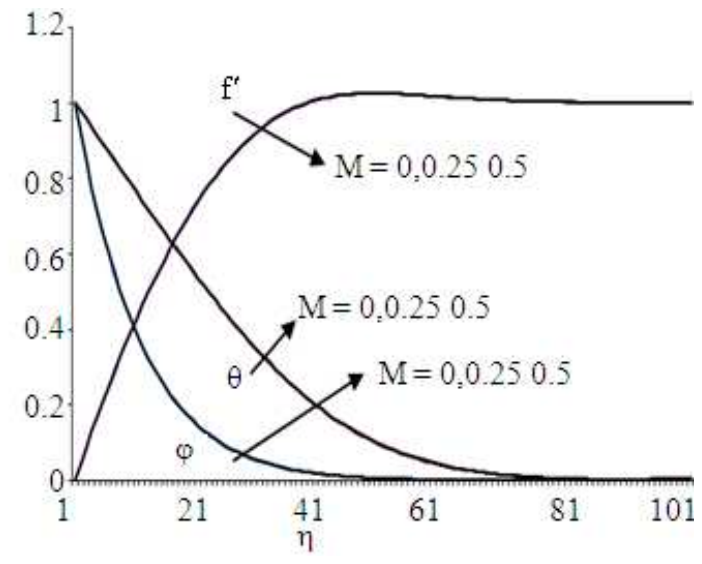

Fig. 4: Velocity, temperature and concentration profiles for various values of $\mathrm{M}$

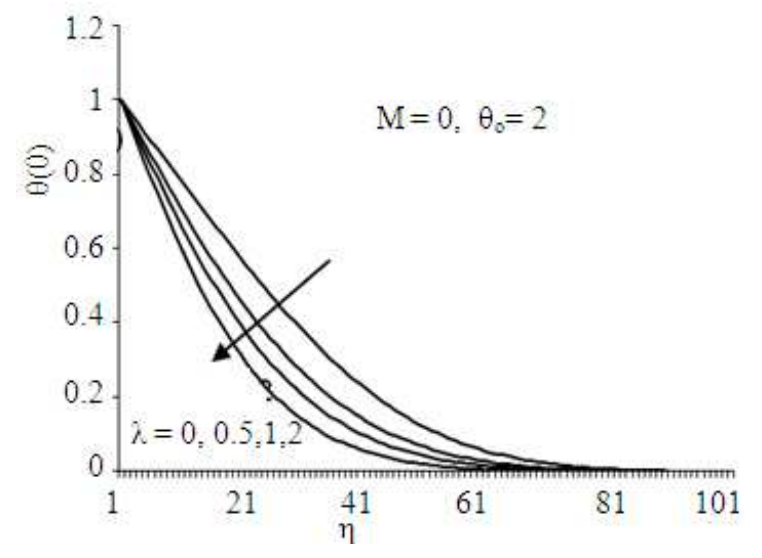

Fig. 5: Temperature profile

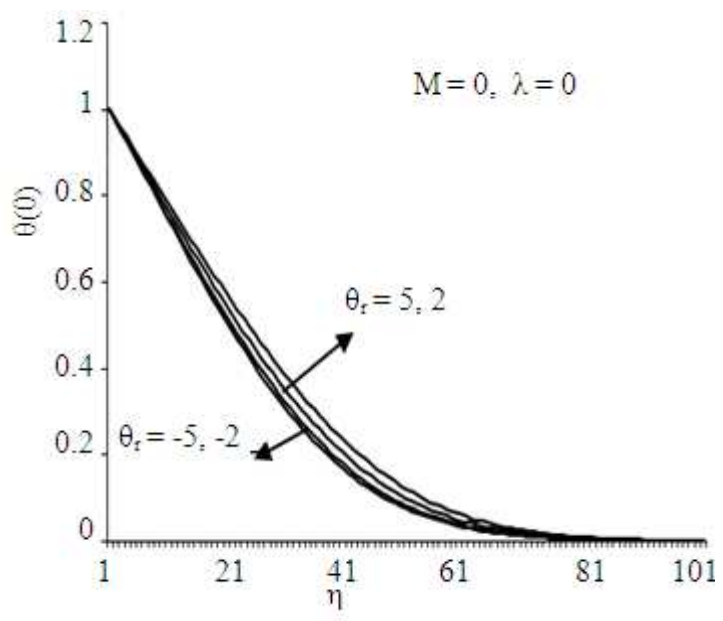

Fig. 6: Temperature profile

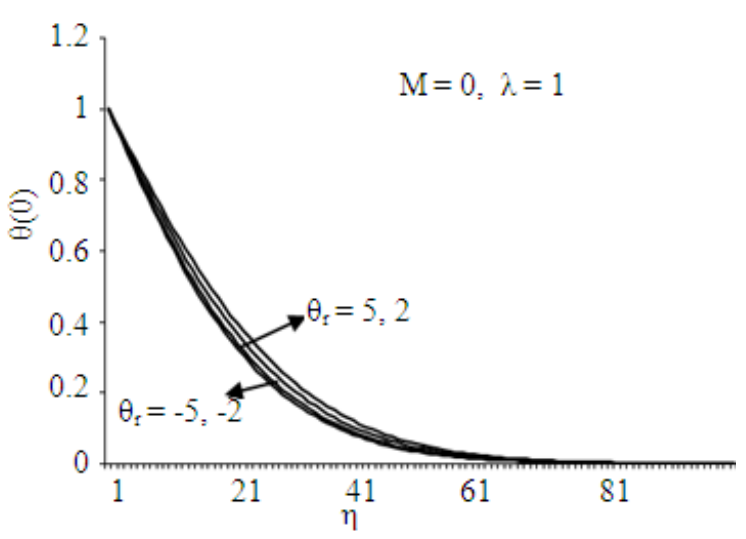

Fig. 7: Temperature profile

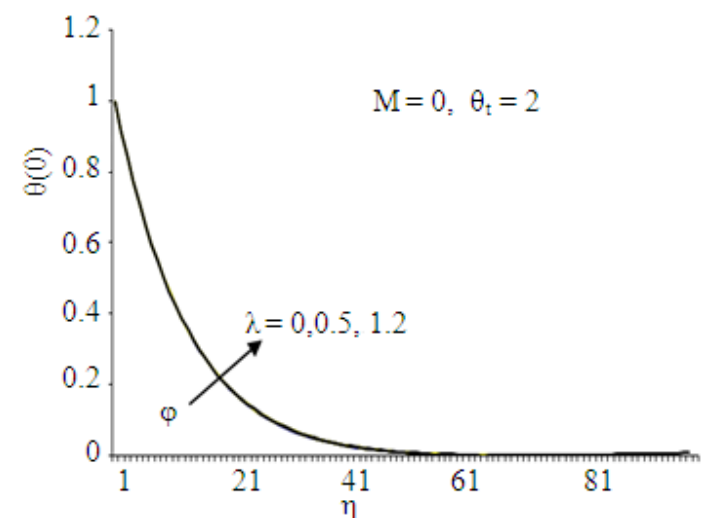

Fig. 8: Concentration profile

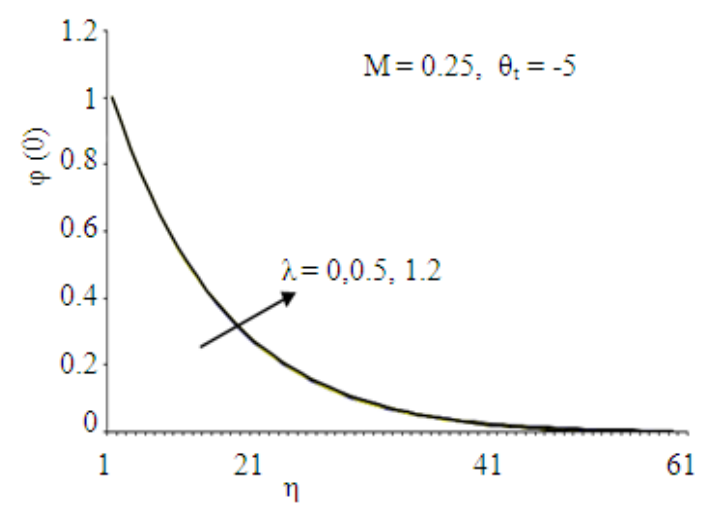

Fig. 9: Concentration profile

It is gleaned from Fig. 5 that the temperature decreases with an increase in the power law index $\lambda$ for $M=0$ and $\theta_{\mathrm{r}}=2$. From Fig. 6-7, it is noted that the temperature decreases as the variable viscosity $\theta_{\mathrm{r}}$ increases for $\mathrm{M}=0, \lambda=0$ and $\mathrm{M}=0, \lambda=1$ respectively. 


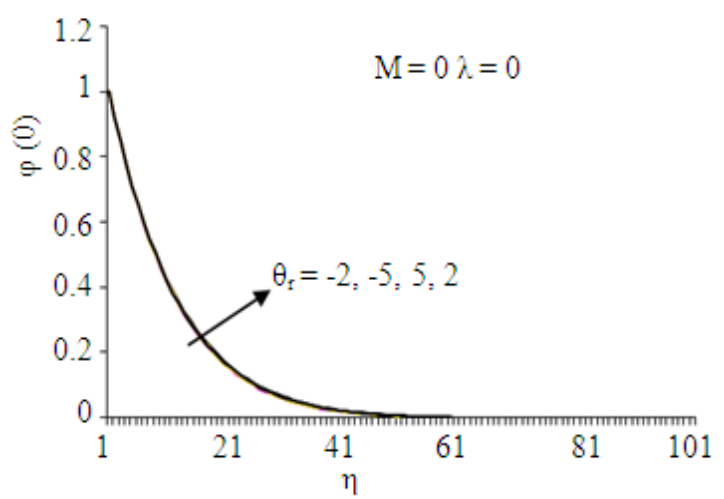

Fig. 10: Concentration profile

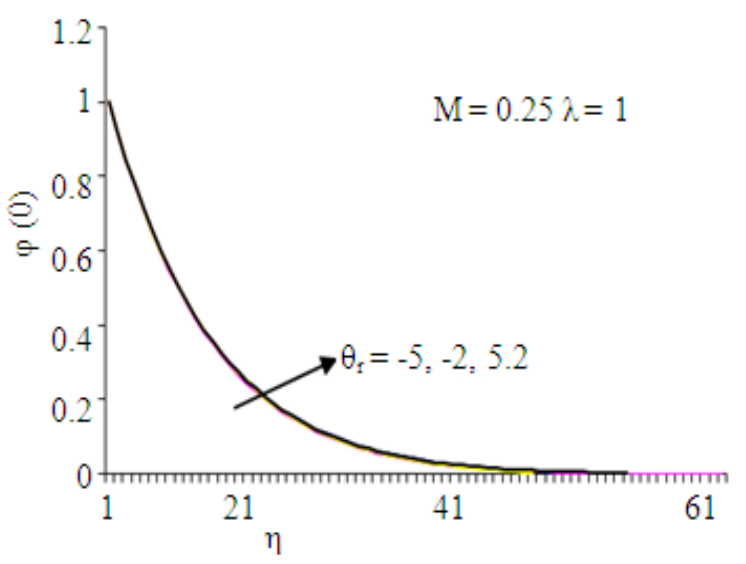

Fig. 11: Concentration profile

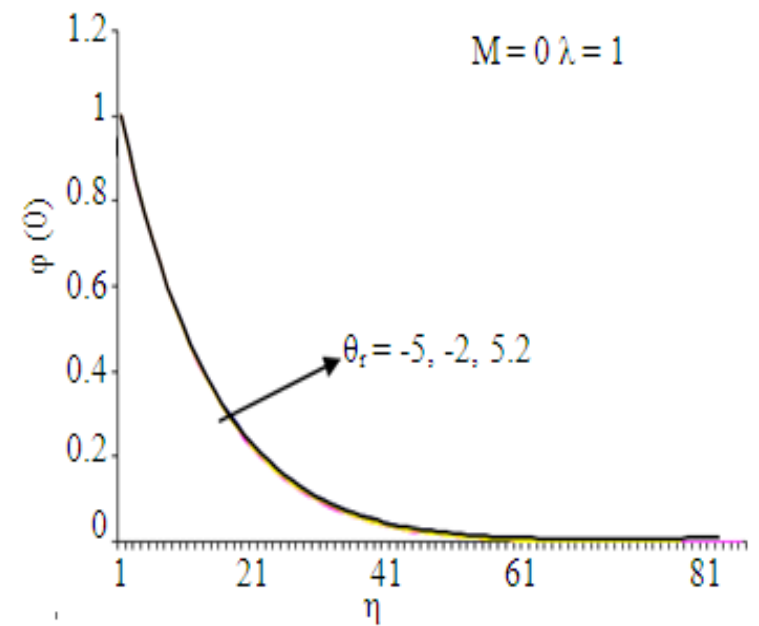

Fig. 12: Concentration profile

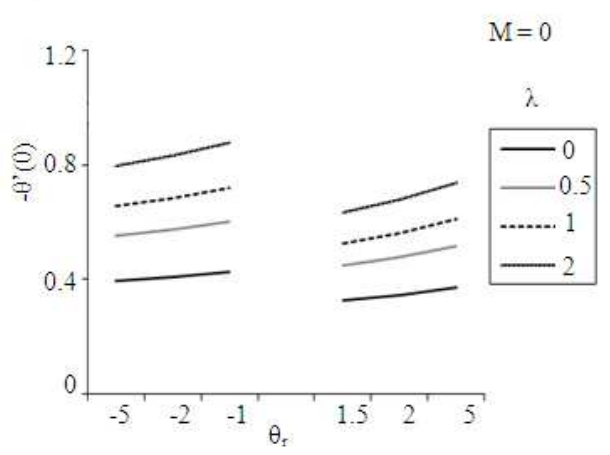

Fig. 13: Nusselt graph

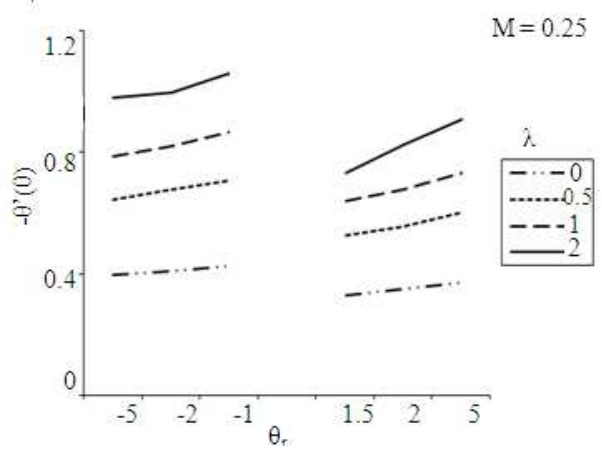

Fig. 14: Nusselt graph

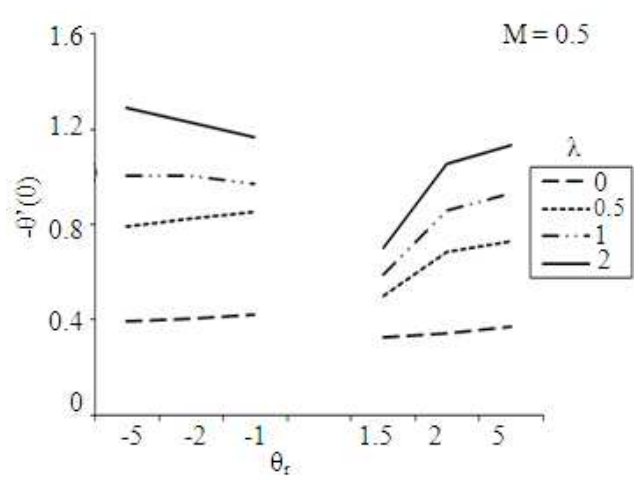

Fig. 15: Nusselt graph

Table 1: Effects of various parameters on $\mathrm{f}^{\prime \prime}(0),-\theta$ '(0) and - $\phi^{\prime}(0)$ with $\operatorname{Re} x=3.0$

\begin{tabular}{llllll}
\hline$\theta \mathrm{r}$ & $\gamma$ & $\mathrm{f} \mathrm{w}$ & $\mathrm{f}^{\prime \prime}(0)$ & $-\theta^{\prime}(0)$ & $-\phi^{\prime}(0)$ \\
\hline 2 & 1.0 & 0.5 & 0.75782 & 0.462570 & 1.433080 \\
6 & 1.0 & 0.5 & 1.16975 & 0.489696 & 1.438034 \\
10 & 1.0 & 0.5 & 1.24642 & 0.494073 & 1.438900 \\
2 & 1.0 & 0.3 & 0.73695 & 0.414260 & 1.401134 \\
2 & 1.0 & 0.5 & 0.75782 & 0.462570 & 1.433280 \\
2 & 1.0 & 1.0 & 0.81628 & 0.592720 & 1.515950 \\
2 & 0.5 & 0.5 & 0.78917 & 0.467096 & 1.054750 \\
2 & 1.0 & 0.5 & 0.75782 & 0.462570 & 1.433080 \\
2 & 3.0 & 0.5 & 0.71330 & 0.457080 & 2.404720 \\
\hline
\end{tabular}


It also shows that the viscosity has its own influence on temperature distribution. From Fig. 3, it is seen that the temperature decreases as the variable viscosity $\theta_{\mathrm{r}}$ increases for $\mathrm{M}=0, \lambda=0$. This is also true for negative values of $\theta_{\mathrm{r}}$. In Fig. 4, the temperature profiles are same irrespective of $M$. This shows that the thermal stratification parameter $M$ has very low influence on temperature distribution. Conversely, it is justified that as temperature increases viscosity effect decreases.

It is understood from Fig. 8 that the concentration profiles are identical irrespective of $\lambda$ for $M=0$ and $\theta_{r}$ $=2$. They are also same for $M=0.5$ and $\theta_{\mathrm{r}}=-5$ irrespective of $\lambda$ which is shown in Fig. 9.

From Fig. 10-12 it is obvious that the concentration profiles are same irrespective of $\theta_{\mathrm{r}}$ for $\mathrm{M}=0, \lambda=0 ; \mathrm{M}$ $=0.25, \lambda=1$ and $\mathrm{M}=0, \lambda=1$ respectively. Besides this from Fig. 3 it is also understood that the concentration profiles are identical irrespective of $\theta_{\mathrm{r}}$, the variable viscosity for $M=0$ and $\lambda=0$.From Fig. 4 , it is understood that the concentration profiles are same irrespective of $\mathrm{M}$. This shows that the thermal stratification parameter $M$ and variable viscosity parameter $\theta_{\mathrm{r}}$ have very low influence on concentration distribution.

Figures 13-15 give the values of - $\theta^{\prime}(0)$ against $\lambda$, the power law index, $M$ the parameter influences thermal stratification effect and $\theta_{\mathrm{r}}$, the variable viscosity parameter. From Fig. 13, it is clear that as $\lambda$ increases the Nusselt number increases rapidly for $\theta_{\mathrm{r}}>$ 0 as well as $\theta_{\mathrm{r}}<0$, in the absence of thermal stratification effect $(\mathrm{M}=0)$. It is also true for $\mathrm{M}=0.25$. For a particular case, $\mathrm{M}=0.5$, the Nusselt number increases rapidly as $\lambda$ increases. This is true for $\theta_{\mathrm{r}}>0$ but for $\theta_{\mathrm{r}}<0$, the Nusselt number decreases for $\lambda=1$ and $\lambda=2$ whereas for $\lambda=0,0.5$ it increases.

Table 1 presents the effect of $\theta_{\mathrm{r}}, \gamma$ and $\mathrm{f}_{\mathrm{w}}$ on the skin friction coefficient $f$ " $(0)$, the Nusselt number$\theta^{\prime}(0)$ and the Sherwood number as $-\phi^{\prime}(0)$. The results reveal that the skin-friction coefficient, the Nusselt number and the Sherwood number increases as $\theta_{\mathrm{r}}$ or $\mathrm{f}_{\mathrm{w}}$ increases. Also, as the chemical reaction parameter $\gamma$ increases, the skin-friction coefficient and the Nusselt number decrease while the Sherwood number increases. To verify the accuracy of the numerical method, the values of $f^{\prime \prime}(0)$ and $-\theta^{\prime}(0)$ for $\mathrm{Gr}=\mathrm{Gc}=0, \theta_{\mathrm{r}}=0.2$ and $\operatorname{Pr}=0.7$ are $-0.19064,0.26415$ respectively as reported in (Bird et al., 1992). But in the present study, the results for $\mathrm{f}^{\prime \prime}(0)$ and $-\theta^{\prime}(0)$ for $\mathrm{Gr}=\mathrm{Gc}=0, \theta_{\mathrm{r}}=0.2$ and $\mathrm{Pr}=0.7$ are 1.075519 and 0.425167 respectively. This proves that there is an error in the values of $\mathrm{f}^{\prime \prime}(0)$ and $-\theta^{\prime}(0)$ produced by Mostafa A.A.Mahmoud (Bird et al., 1992).

\section{CONCLUSION}

The effects power law index, variable viscosity and thermal stratification parameter on heat and mass transfer of a steady incompressible Newtonian fluid past a vertical plate have been studied numerically using the RK Gill method together with the shooting technique. From the previous results and discussion, we conclude the following:

- The velocity decreases with the increase of power law index but the velocity increases with the increase of variable viscosity and the velocity is identical irrespective of $\mathrm{M}$, the thermal stratification parameter

- The temperature decreases with the increase of the variable viscosity or the power law index, whereas the temperature is same irrespective of $\mathrm{M}$, the thermal stratification parameter

- The concentration is identical irrespective of the variable viscosity, thermal stratification parameter and the power law index

- The skin-friction coefficient, the Nusselt number and the Sherwood number increases as the viscosity or suction parameter increases

- The skin-friction coefficient and the Nusselt number decrease with the increase of the chemical reaction parameter but the Sherwood number increases as the chemical reaction parameter increases.

- These findings have their own application in Geothermal system, Nuclear reactors, Petrol Engineering. For the purpose of engineering application, the operating temperature difference is taken as $80 \mathrm{~K}$. This gives $\theta_{\mathrm{r}}=5.62$ for air and $\theta_{\mathrm{r}}=$ 0.37 for water. From the computed values, it is found that with the assumption of constant viscosity, the heat transfer coefficient is $4.3 \%$ higher than that of the present result for air and in the case of water it is about $43.9 \%$ lower. Hence, the neglect of viscosity variation in liquids may result in serious error in the calculation of heat transfer coefficient.

\section{ACKNOWLEDGEMENT}

The research render their heartfelt thanks to Dr. T. Govindarajulu former Professor and Head of Department of Mathematics, Anna University, Chennai for his generous help. The authors wish to thank the Director IRT Chennai and the Principal IRTT, Erode for their generous help. The authors wish to thank the Chairman, Director, Chief Executive, Principal, Bannari Amman Institute of Technology for their support to do this study. 
Am. J. Applied Sci., 8 (6): 628-634, 2011

\section{REFERENCES}

Andersson, H.I., O.R. Hansen and B. Holmedal, 1994. Diffusion of a chemical reactive species from a stretching sheet. Int. J. Heat Mass Trans., 37: 659664. http://cat.inist.fr/?aModele $=$ afficheN\&cpsidt $=4035$ 303

Apelblat, A., 1982. Mass transfer with a chemical reaction of the first order. Effect of axial diffusion. Chem. Eng. J., 23: 1s93-203.

Bird, R.B., W.E. Stewart and E.N. Lightfoot, 1992. Transport Phenomena. John Wiley and Sons, New York, USA, 2nd Edn., 1-885. ISBN: 0-471-41077-2

Chamkha, A.J. 2003. MHD flow of a uniformly stretched vertical permeable surface in the presence of heat generation/absorption and a chemical reaction. Int. Commun. Heat Mass Trans., 30: 413422. DOI:10.1016/s0735-1933(03)00059-9

Cussler, E.L., 1988. Diffusion Mass Transfer in Fluid Systems, Cambridge University Press, London, UK. Rev. Edition. 1-654.

Das, U.N., R. Deka and V.M. Soundalgekar, 1994. Effects of mass transfer on flow past an impulsively started infinite vertical plate with constant heat flux and chemical reaction. Forschung im Ingenieurwesenn, 60: 284287.DOI:10.1007/BF02601318

Fan, J.R., J.M. Shi and X.Z. Xu, 1997. Similarity solution of mixed convection over a horizontal moving plate, Heat and Mass Trans., 32: 199-206. DOI:10.1007/s002310050112

Gebhart, B. and L.Pera, 1971. The nature of vertical natural convection flows resulting from the combined buoyancy effects of thermal and mass diffusion. Int. J. Heat Mass Trans., 14: 20252050.DOi:10.1016/0017-9310(71)90026-3

Hady, F.M., A.Y.Bakier and R.S.R. Gorla, 1996. Mixed convection boundary layer flow on a continuous flat plate with variable viscosity, Heat Mass Trans., 31: 169-172. DOI:10.1007/BF02333315

Herwing, H. and G. Wickern,1986. The effect of variable properties on laminar boundary layer flow Warme-und Stoffubctragung, 20:47-54. DOI: 10.1007/BF00999737
Hossain, A. and S. Munir, 2000. Mixed convection flow from a vertical flat plate with temperature dependent viscosity. Int. J. Thermal Sci., 39:173183.DOI: 10.1016/81290-0729(00)00237-4

Kafoussias, N.G., D.A.S. Rees and J.E. Daskalakis, 1998. Numerical study of the combined free-forced convective laminar boundary layer flow past a vertical isothermal flat plat with temperaturedependent viscosity. Acta Mech., 127: 39-50.

Kafoussius, N.G. and E.W. Williams, 1995. The effect of temperature-dependent viscosity on free-forced convective laminar boundary layer flow past a vertical isothermal flat plate, Acta Mech., 110: 123-137.DOI:10.1007/BF01215420

Kandasamy, R., K. Periasamy and K.K. Sivagnana Prabhu, 2005. Effects of chemical reaction, heat and mass transfer along a wedge with heat source and concentration in the presence of suction or injection. Int. J. Heat Mass Trans., 48: 1388-1394. DOI:10.1016/j.ijheatmasstransfer.2004.10.008

Lai, F.C. and F.A. Kulachi, 1990. The effect of variable viscosity on convective heat transfer along a vertical surface in a saturated porous medium. Int. J. Heat Mass Trans., 33: 1028-1031.

Mahmoud, M.A.A., 2007. A Note on variable viscosity and chemical reaction effects on mixed convection heat and mass transfer along a semi-infinite vertical plate. Math. Problems Eng. ISBN: 0080438784,1668, Volume 2007 (2007), Article ID 41323, 7 pages, DOI:1155/2007/41323

Muthucumaraswamy, R. and P.Ganesan, 2001. Effect of the chemical reaction and injection on flow characteristics in an unsteady upward motion of an isothermal plate, J. Applied Mech. Tech. Phys., 42: 665-671.

Pop, I. and D.B. Ingham ,2001. Convective Heat Transfer, Mathematical and Computational Modeling of Viscous Fluid and Porous Media, Pergamon, London, UK.

Takhar, H.S., A.J. Chamkha and G. Nath, 2000. Flow and mass transfer on a stretching sheet with a magnetic field and chemically reactive species, Int. J. Eng. Sci., 38: 1303-1314.DOI: 10.1016/s00207225(99)00079-8 